\title{
Maintenance treatment of gastroesophageal reflux disease: An evaluation of continuous and on-demand therapy with rabeprazole $20 \mathrm{mg}$
}

\author{
David G Morgan MD MSc FRCPC ${ }^{1}$, Michael FJ O'Mahony MB ChB FRCPC ${ }^{2}$, William F O'Mahony MB ChB BAO ${ }^{3}$, \\ Jean Roy $\mathrm{MD}^{4}$, Fernando Camacho $\mathrm{PhD}^{5}$, Julie Dinniwell $\mathrm{MSc}^{6}, \mathrm{GLA}$ Horbay $\mathrm{PhD}^{6}$, \\ Farah A Husein-Bhabha BSc Phm ; for the RAB-GRD-3002 Study Group
}

\begin{abstract}
DG Morgan, MFJ O’Mahony, WF O'Mahony, et al; for the RABGRD-3002 Study Group. Maintenance treatment of gastroesophageal reflux disease: An evaluation of continuous and on-demand therapy with rabeprazole $20 \mathrm{mg}$. Can J Gastroenterol 2007;21(12):820-826.
\end{abstract}

OBJECTIVE: To evaluate continuous therapy (COT) and on-demand therapy (ODT) with rabeprazole $20 \mathrm{mg}$ for maintenance in uninvestigated gastroesophageal reflux disease (GERD).

METHODS: This randomized, open-label study enrolled 331 GERD (heartburn-predominant) patients with a pre-existing proton pump inhibitor history of one month or longer, to an acute four-week trial with $20 \mathrm{mg}$ rabeprazole daily for heartburn management. Patients who achieved satisfactory heartburn control during the acute phase (three days or less of heartburn, with no more than one episode rated as moderate, and heartburn rated satisfactorily or completely controlled with minimal rescue antacid use in the seven days preceding randomization) were randomly assigned to six months of rabeprazole $20 \mathrm{mg}$ given as either daily COT or daily ODT, which was initiated upon symptom recurrence and stopped upon symptom resolution. Rescue antacid usage was permitted and tracked. Primary efficacy was measured as the proportion of heartburn-free days over six months. RESULTS: For the 268 patients, the mean percentage of heartburnfree days for the COT group and for the ODT group were $90.3 \% \pm 14.8 \%$ and $64.8 \% \pm 22.3 \%$, respectively $(\mathrm{P}<0.0001)$. COT was associated with an increased number of medication intake days $(154 \pm 40.2)$ versus ODT $(68 \pm 46.1)$, with less heartburn episodes observed with COT versus ODT, respectively $(n=7, n=26$, $\mathrm{P}<0.0001$ ). Ninety-two per cent of COT patients and $79 \%$ of ODT patients were either 'satisfied' or 'very satisfied' with treatment. The mean usage of antacids was low and similar in both groups. COT and ODT regimens were safe and well-tolerated, with a similar incidence of adverse events.

CONCLUSION: Results based on symptom assessments favour COT with rabeprazole $20 \mathrm{mg}$ for maintenance therapy in patients with uninvestigated GERD; however, both therapy types are safe and acceptable treatment options for selected patients.

Key Words: Continuous therapy; GERD; Heartburn; Maintenance; On-demand therapy; Rabeprazole

\section{Le traitement d'entretien du reflux gastro-} œsophagien pathologique : Une évaluation du traitement ininterrompu et sur demande avec $20 \mathrm{mg}$ de rabéprazole

OBJECTIF : Évaluer le traitement ininterrompu (TI) et le traitement sur demande (TSD) à l'aide de $20 \mathrm{mg}$ de rabéprazole pour le traitement d'entretien d'un reflux gastro-œsophagien pathologique (RGOP) non exploré. MÉTHODOLOGIE : Cette étude aléatoire ouverte a porté sur 331 patients atteints de RGOP (surtout des brûlures d'estomac) ayant déjà pris des inhibiteurs de la pompe à proton pendant au moins un mois, participant à un essai aigu de quatre semaines au cours desquelles ils prenaient 20 mg de rabéprazole par jour pour traiter leurs brûlures d'estomac. Les patients qui contrôlaient leurs brûlures d'estomac de manière satisfaisante pendant la phase aiguë (trois jours ou moins de brûlures d'estomac, pas plus d'un épisode classé moyen et brûlures d'estomac classées comme satisfaisantes ou complètement contrôlée avec un usage minime d'anti-acides de sauvetage dans les sept jours précédant la randomisation) ont été divisés au hasard entre la prise de $20 \mathrm{mg}$ de rabéprazole pendant six mois, administrée sous forme de TI quotidien ou de TSD quotidien, entrepris à la récurrence des symptômes et interrompu à leur disparition. L'utilisation d'anti-acides de sauvetage était autorisée et suivie. L'efficacité primaire était mesurée selon la proportion de journées sans brûlures d'estomac pendant six mois.

RÉSULTATS : Pour les 268 patients, le pourcentage moyen de journées sans brûlures d'estomac pour le groupe ayant le TI et le groupe ayant le TSD était de $90,3 \% \pm 14,8 \%$ et de $64,8 \% \pm 22,3 \%$, respectivement $(\mathrm{P}<0,0001)$. Le TI s'associait à un plus grand nombre de jours de prise de médicament $(154 \pm 40,2)$ que le TSD $(68 \pm 46,1)$ et à moins d'épisodes de brûlures d'estomac $(n=7, n=26, P<0,0001)$. Quatre-vingt-douze pour cent des patients ayant le TI et $79 \%$ de ceux ayant le TSD étaient soit « satisfaits ", soit " très satisfaits » du traitement. Le recours moyen aux antiacides était faible et similaire dans les deux groupes. Le TI et le TSD étaient sécuritaires et bien tolérés. Leur incidence et leurs effets néfastes étaient similaires

CONCLUSION : Les résultats fondés sur l'évaluation des symptômes favorisent le TI avec $20 \mathrm{mg}$ de rabéprazole pour le traitement d'entretien des patients atteints d'une RGOP non explorée. Cependant, les deux types de traitement sont sécuritaires et acceptables pour certains patients.

(4). The aims of long-term management of symptoms include adequate symptom control, prevention of complications and improvement in quality of life (5). In patients with frequent relapse, maintenance therapy is recommended, ideally utilizing the minimal dose of medication required to relieve symptoms astroesophageal reflux disease (GERD) is a recurring conJition that often requires long-term maintenance therapy $(1,2,3)$. Regardless of endoscopic status at diagnosis, the majority of GERD patients will experience relapse within six months of cessation of short-term acid suppression therapy
${ }^{1}$ Division of Gastroenterology, St Joseph's Healthcare, Hamilton; ${ }^{2}$ London Road Diagnostic Clinic, Sarnia, ${ }^{3}$ Medical Research Centre, Corunna,

Ontario; ${ }^{4}$ Clinique Medicale Les Saules, Les Saules, Quebec; ${ }^{5}$ DAMOS Inc; ${ }^{6}$ Clinical Affairs, Janssen-Ortho Inc, Toronto, Ontario

Correspondence: Dr David Morgan, Division of Gastroenterology, St Joseph's Healthcare, 50 Charlton Avenue East, Hamilton, Ontario

L8N 4A6. Telephone 905-574-7721, fax 905-575-2661, e-mail morgand@mcmaster.ca

Received for publication December 21, 2006. Accepted March 27, 2007 
(1). Proton pump inhibitors (PPIs) are a first-line therapy for GERD because they provide the most potent acid inhibition with the fastest relief of symptoms when taken continuously $(5,6)$. Management options for PPI therapy are daily (continuous), intermittent fixed courses, or on-demand regimens (5).

'On-demand' medical therapy is a patient-driven strategy defined as the daily intake of a medication for a period of time sufficient to achieve resolution of the individual's refluxrelated symptoms. Following symptom resolution, the medication is discontinued until the individual's symptoms recur, at which point medication is again taken daily until the symptoms resolve. On-demand therapy (ODT) also has important economic implications, in terms of reduced drug intake and possibly reduced health care costs (4).

Patients with an endoscopically confirmed diagnosis of GERD and positive symptomatic response to a course of daily PPI therapy have been successfully managed subsequently using ODT $(5,7,8)$.

After six months of ODT with omeprazole $20 \mathrm{mg}, 10 \mathrm{mg}$ or placebo, Lind et al (9) observed that $83 \%$ of patients on omeprazole $20 \mathrm{mg}, 69 \%$ of patients on omeprazole $10 \mathrm{mg}$ and $56 \%$ of placebo patients were willing to continue in the study, suggesting that ODT is an effective treatment strategy for nonerosive GERD (NERD) patients. Bytzer et al (7) also achieved favourable results in a six-month trial of on-demand rabeprazole $10 \mathrm{mg}$ in patients with NERD, and reported a statistically significant difference in favour of on-demand rabeprazole versus placebo, measured as rates of discontinuation due to inadequate heartburn control versus placebo $(\mathrm{P}<0.00001)$.

Ponce et al (8) investigated ODT in an expanded population, including NERD patients and patients with low-grade esophagitis. Symptom control was maintained in over $85 \%$ of patients during six months of on-demand rabeprazole $20 \mathrm{mg}$ therapy, following a four-week daily run-in period with rabeprazole $20 \mathrm{mg} /$ day. Additionally, PPI consumption was low and patient satisfaction with treatment was high.

Results from the above studies and others are generally consistent, and demonstrate that ODT with a PPI is an appropriate means of managing GERD symptoms in many NERD patients.

In clinical practice, however, particularly in primary care, patients are rarely initially investigated by endoscopy. GERD is diagnosed based on heartburn-predominant symptoms $(1,4)$ and an empiric trial of PPI therapy is the recommended firstline treatment because control of reflux symptoms is the main goal of therapy $(1,3,4)$. For these uninvestigated patients, initial continuous therapy (COT) would establish optimal symptom control, before a switch to non-COT. Most patients treated in primary care do not have severe GERD, and those are the patients for whom non-COT could be expected to be the most effective (1). Frequency of heartburn relapse, number of symptom-free days, symptom severity, the number of days that medications are used and the frequency of need for rescue antacids are all clinically important measures of heartburn (1). 'Acceptable' heartburn control is defined as up to two mild episodes per week (up to one moderate episode per week is another useful measure) because anything greater than this level of symptoms has been associated with a diminished quality of life $(1,10)$.

The best possible long-term management of symptomatic GERD patients has not been established. The present study evaluated both continuous and on-demand maintenance regimens of rabeprazole therapy, in an attempt to provide clinicians with insight into the optimal course of therapy for uninvestigated GERD patients.

\section{Study design}

\section{PATIENTS AND METHODS}

Approximately 350 participants were to be enrolled in this open-label, randomized, controlled, multicentre study, involving 23 Canadian sites between July 2004 and July 2005. The study was conducted in accordance with the principles of the Declaration of Helsinki and the International Conference of Harmonization for Good Clinical Practice (11), and ethics approvals were obtained from central or local ethics committees, as applicable. Written informed consent was obtained from each participant before enrolment. Clinical study monitors conducted regular monitoring visits to ensure protocol adherence. Study participants were screened and enrolled into a four-week, open-label, acute treatment phase in which all patients received rabeprazole $20 \mathrm{mg}$ once per day in the morning. After this four-week phase, those eligible to continue were subsequently randomly assigned to either $20 \mathrm{mg}$ rabeprazole ODT or $20 \mathrm{mg}$ once daily COT (in a 1:1 ratio) for up to six months. The daily dose in each study phase was taken as two $10 \mathrm{mg}$ tablets (Pariet, Janssen-Ortho Inc, Canada). Participants attended the clinic for five study visits: baseline and screening (day -28), randomization (day 0), and at one, three and six months postrandomization. Telephone contacts were conducted at week 2 and months 2, 4 and 5 .

\section{Participants}

Male and female participants with a minimum three-month history of GERD, with heartburn as the predominant symptom, were enrolled into the acute phase of the trial if they met the following eligibility criteria: 25 to 65 years of age, on continuous PPI therapy (including rabeprazole) for at least one month before enrolment, with adequate heartburn control (defined as no severe episodes and no more than one moderate episode of heartburn in the seven days before screening). Patients had to provide written informed consent and be able to complete the study requirements. To be eligible for participation in the six-month maintenance phase, patients must have had satisfactory heartburn control in the final week of the acute four-week phase, defined as not more than three days of heartburn, with no more than one episode rated as moderate, and heartburn rated satisfactorily or completely controlled in the seven days preceding randomization, with minimal rescue antacid usage. Participants were excluded if they had a known hypersensitivy to rabeprazole or any substituted benzimidazole, or had taken a histamine-2 receptor antagonist within two weeks of screening. Other exclusion criteria included any significant gastrointestinal history (including the presence of alarm symptoms such as vomiting, blood in stool, anemia and dysphagia), known history of Barrett's esophagus, esophageal stricture, pyloric stenosis, known gastric or duodenal ulcer, infectious or inflammatory conditions of the small or large intestine, malabsorption syndromes, obstruction, a history of gastrointestinal malignancy, or prior gastric or intestinal surgery (including vagotomy, but excluding appendectomy and cholecystectomy), and chronic constipation uncontrolled by treatment regimen. Other significant medical conditions likely to interfere with the health of the subject during the study, with the conduct of the study and/or interpretation of results were also exclusionary. Women were required to be postmenopausal, 
or not pregnant or lactating, using an effective method of birth control throughout the study, and to have a negative urine pregnancy test before enrolment. Patients requiring continuous concurrent treatment with other medications used to treat upper or lower gastrointestinal conditions were excluded. Use of other nonstudy antacids or other acid suppressive medication was prohibited during the study. High-dose systemic corticosteroids were also prohibited; opioids and nonsteroidal anti-inflammatories were permitted only if used occasionally and intermittently for self-limited conditions, or if patients were taking a stable dose before and throughout the study.

\section{Study treatment and assessments}

During the first visit, demographic data, medical, surgical and medication histories were recorded for all eligible participants, and a urine sample was taken from women for pregnancy testing. Patients were assessed via questionnaire to confirm heartburn as the predominant symptom (described as a burning feeling rising from the stomach or lower chest toward the neck) $(12,13)$. The occurrence and severity of heartburn symptoms during the previous week was recorded using a questionnaire. Treatment was started with rabeprazole $20 \mathrm{mg}$ once daily for four weeks. Patients were instructed to limit supplemental antacid usage (Maalox Extra Strength Tablets $1000 \mathrm{mg}$, Novartis Consumer Health Canada Inc, Canada) to the minimum required to achieve symptomatic relief. Heartburn occurrence, and worst overall severity on days with heartburn, medication compliance and antacid usage were recorded in a daily diary. Severity was assessed as $0=$ none; $1=$ mild (present but causing little or no discomfort and can be ignored when not thought about); 2 =moderate (cannot be ignored but does not influence daily routine); 3 =severe (causes discomfort and some interference with daily routine); or $4=$ very severe (disabling and interferes considerably with daily routine). The diary also included weekly assessments in which patients rated heartburn control as 'no control', 'poorly controlled', 'satisfactorily controlled' or 'completely controlled' (1), and satisfaction with heartburn control as 'very dissatisfied', 'dissatisfied', 'neither satisfied nor dissatisfied', 'satisfied' or 'very satisfied' (2), at the end of each week. Subjects assigned to the COT group took rabeprazole $20 \mathrm{mg}$ daily. Subjects randomly assigned to the ODT group were instructed to initiate treatment when heartburn occurred by taking rabeprazole $20 \mathrm{mg}$ on the first day of symptoms, and one dose each subsequent morning for as many days as required for symptom resolution, stopping when participants were satisfied with their heartburn control. All subjects completed the daily diary throughout the maintenance phase.

The primary end point of the study was the proportion of heartburn-free days during the six-month maintenance phase, based on symptom occurrence, as recorded in the daily diary.

\section{Additional predefined assessments}

GERD symptoms: Heartburn and 14 other GERD-specific symptoms were evaluated at study entry, baseline of maintenance phase (end of the four-week acute phase), and at one, three and six months or study termination of the maintenance phase, using the GERD symptoms assessment scale (GSAS) (14). Scores were tabulated for four subscales: symptom occurrence (yes or no), frequency of symptom occurrence (number of times per week), symptom severity ( 1 =slight, $2=$ moderate, $3=$ severe, $4=$ very severe) and symptom distress or bother
$(0=$ not at all, $1=$ somewhat, $2=$ quite a bit, $3=$ very much) . Lower subscale scores indicated better health.

Quality of life: Quality of life was evaluated at the same time points as the GSAS, using the patient assessment of upper gastrointestinal disorders - quality of life questionnaire (PAGIQOL) (15). Scores were tabulated using a five-point categorical scale $(0=$ none of the time to $5=$ all of the time $)$ for five domain scales: daily activities (10 items), clothing (2 items), diet and food habits (7 items), relationships (3 items), and well-being and distress ( 8 items). The range for total PAGI-QOL and domain scores was from 0 to 5 , with a better health condition indicated by lower scores.

Overall treatment evaluation - physician and subject: The overall effect of the medication regimen on heartburn control over the duration of the maintenance treatment period ('very poor', 'poor', 'no change', 'good' or 'very good') was assessed by the physician and patient at study termination; patients were also asked to rate their overall satisfaction with their heartburn control during the same period ('very dissatisfied', 'dissatisfied', 'neither dissatisfied nor satisfied', 'satisfied' or 'very satisfied'). Safety: The physical examination, including weight and vital signs, was performed at weeks 4 and 8 , and at study termination. All emergent adverse events (spontaneously reported, elicited by questioning, or clinically significant changes in physical parameters) were recorded from the first study-related procedure to the last study-related procedure.

\section{Statistics}

The primary variable for analysis was the percentage of heartburn-free days. The difference in the percentage of heartburn-free days in the ODT group versus the COT group over the six-month maintenance phase was estimated together with the $95 \% \mathrm{CI}$ on an intention-to-treat basis. It was estimated that if there was a $15 \%$ difference or less between the two types of treatments, they would be considered clinically equivalent (ie, one-half of the length of the $95 \%$ CI to estimate the difference between the percentage of heartburn-free days for the ODT group and the COT group would be less than or equal to $30 \%$ of the size of the SD of the treatment group populations). This assumed that both treatment group populations would have the same variance and approximate normal distributions. The power calculation was based on a minimum of 85 patients completing treatment in each arm. For all secondary variables, between-group comparisons were made on an intention-to-treat basis using the two sample $t$ test (continuous response) or the Fisher's exact test (categorical response). When appropriate, comparisons were also performed by nonparametric analyses. The analyses were adjusted for factors and covariates (such as age, sex, baseline values, etc). In such cases, the generalized linear model or logistic regression model were applied to test the significance of treatment effect. All statistical tests were two-sided and at the 0.05 significance level; no adjustments were done for multiple comparisons. The safety population comprised all patients taking at least one dose of study medication. Descriptive statistics and appropriate tests were used to summarize and analyze adverse events data.

\section{Disposition}

\section{RESULTS}

A total of 331 participants were enrolled in the acute phase of the study and 268 (COT, $n=137$; ODT, $n=131$ ) were randomly assigned to receive maintenance study treatment. In total, 
TABLE 1

Baseline demographic and clinical characteristics of patients

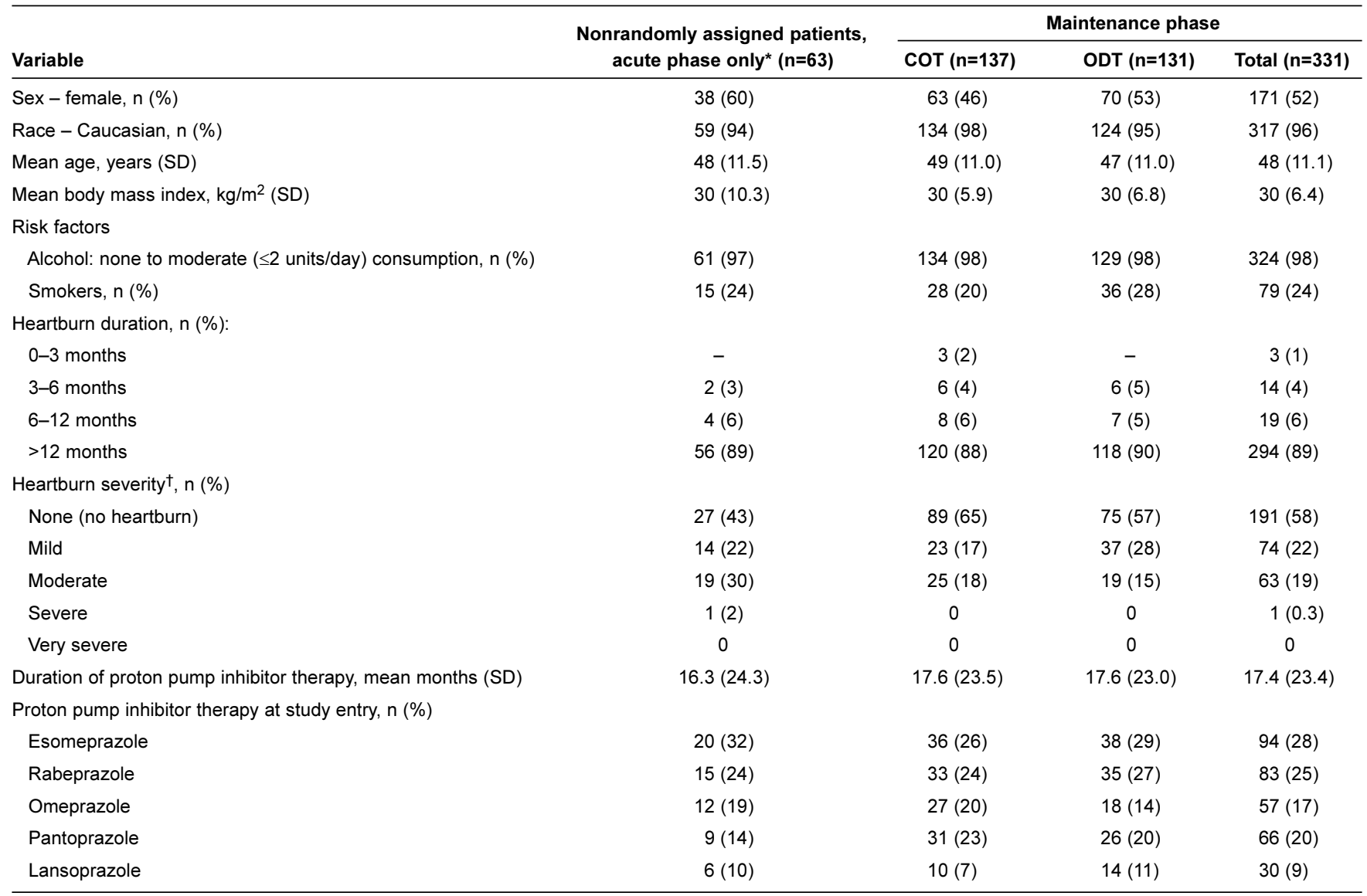

${ }^{*}$ Received rabeprazole in the acute phase, but was not randomized to the maintenance phase; ${ }^{\dagger}$ Based on the maximum reported severity at baseline. COT Continuous therapy; ODT On-demand therapy

234 participants $(87 \%)$ completed six months of maintenance treatment. Of the 34 participants (13\%) who withdrew before completing the study, nine $(3 \%)$ withdrew due to poor heartburn control during the maintenance treatment phase, eight $(3 \%)$ were lost to follow-up, six $(2 \%)$ withdrew due to an adverse event, five (2\%) withdrew consent, two (1\%) were withdrawn due to noncompliance, two $(1 \%)$ were withdrawn due to protocol violations, one $(0.4 \%)$ withdrew due to pregnancy and one $(0.4 \%)$ withdrew for other reasons.

The proportion of patients who discontinued treatment due to insufficient heartburn control was not significantly different between COT (2.2\%) and ODT groups (4.6\%; P=0.8690). The mean $( \pm \mathrm{SD})$ time to discontinuation due to poor heartburn control was $83 \pm 59.4$ and $49 \pm 31$ days $(\mathrm{P}=0.2788)$ for the COT and ODT groups, respectively.

Demographic characteristics

Baseline demographic details for the 268 randomly assigned patients are given in Table 1 . Treatment groups were similar with respect to both baseline demographic and clinical characteristics. Testing for Helicobacter pylori was not performed. Of the 331 patients enrolled, 58\% had no heartburn and $23 \%$ had only mild heartburn in the week before screening. Almost all enrolled patients indicated that their heartburn with their current PPI medication at study entry was 'satisfactorily' $(42 \%)$ or 'completely' (57\%) controlled.
Efficacy

Acute phase: Of the 331 patients enrolled into the acute phase of the trial, $92.5 \%$ reported that their heartburn symptoms were either 'satisfactorily' or 'completely' controlled by the end of the four weeks and $89 \%$ of patients were either 'satisfied' or 'very satisfied' with control of their heartburn symptoms; $78 \%$ of patients experienced, at most, mild heartburn during the final week of the acute phase and either mild or no heartburn symptoms $92 \%$ of the days, during the four weeks of acute treatment. Daily mean antacid consumption during the four weeks was $0.2 \pm 0.41$ tablets. Medication and diary compliance were excellent at greater than $90 \%$.

Maintenance phase:

Symptom control: In the randomly assigned group $(n=268)$, all patients reporting heartburn satisfaction $(n=233)$ indicated that their heartburn was 'satisfactorily' or 'completely' controlled at the end of the acute phase. In addition, 99\% of randomly assigned patients were either 'satisfied' or 'very satisfied' with heartburn control before entry into the maintenance phase.

There were significantly more heartburn-free days with COT (90\%) compared with ODT (65\%; P<0.0001, Figure 1). Patients in the COT group reported a larger proportion of weeks with two days or less of heartburn per week, with maximum severity rated mild, than patients in the ODT group (COT 84\% versus ODT 41\%; $\mathrm{P}<0.0001$ ). Heartburn episodes, defined as consecutive days with heartburn, were significantly 


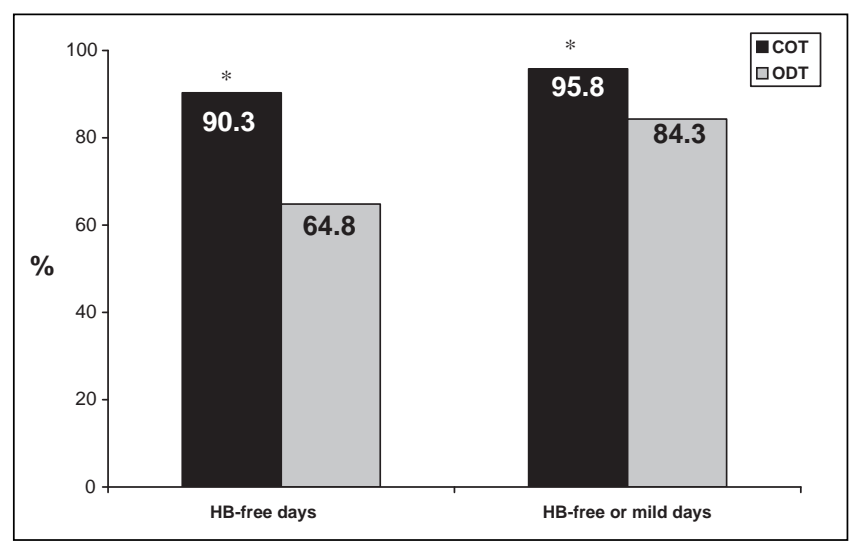

Figure 1) Percentage of heartburn (HB)-free days, and the percentage of HB-free or mild days. $* P<0.0001$. COT Continuous therapy; ODT On-demand therapy

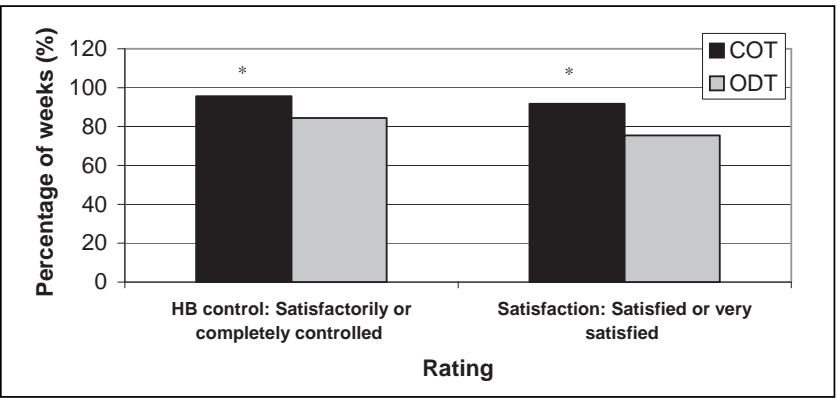

Figure 2) Summary of heartburn (HB) control and HB control satisfaction. $* P<0.001$. COT Continuous therapy; ODT On-demand therapy

less frequent and of shorter duration for the COT group compared with the ODT group, with a mean of $7 \pm 9.1$ heartburn episodes for the COT group compared with $26 \pm 15.7$ heartburn episodes for the ODT group $(\mathrm{P}<0.0001)$, and mean episode duration of $1.4 \pm 2$ days and $4.4 \pm 15.7$ days, respectively $(\mathrm{P}=0.0319)$. Treatment episodes (ODT) were defined as consecutive days of medication intake in response to symptoms; for patients taking ODT, the mean duration of treatment episodes was $4.5 \pm 15.8$ days and the mean interval between treatment episodes was $9.7 \pm 22$ days.

Medication usage: Compliance was excellent over the six-month maintenance treatment period in the continuous therapy group, with study medication intake on more than $97 \%$ of the days. Patients taking ODT took medication approximately $45 \%$ of the days, ie, approximately one dose every 2.2 days. The mean number of supplemental antacid tablets used per day was very low in both groups and was $0.1 \pm 0.3$ for COT and $0.3 \pm 0.4$ for ODT $(\mathrm{P}=0.0023)$.

Ratings of heartburn control and satisfaction: Subjects taking COT rated heartburn as 'satisfactorily' or 'completely' controlled for a significantly greater proportion of weeks compared with ODT (96\% versus $84 \%$, respectively; $\mathrm{P}<0.0001)$. The proportion of weeks that satisfaction was rated 'very satisfied' or 'satisfied' was significantly greater for those taking COT (92\%) compared with ODT $(76 \% ; \mathrm{P}<0.0001)$ (Figure 2).

GERD symptoms and quality of life assessments (GSAS and PAGI-QOL): After completing the four-week acute treatment phase, GSAS and PAGI-QOL scores were low, indicating good health, which was consistent with the study eligibility criteria (ie, enrolled patients had to have adequate symptom control

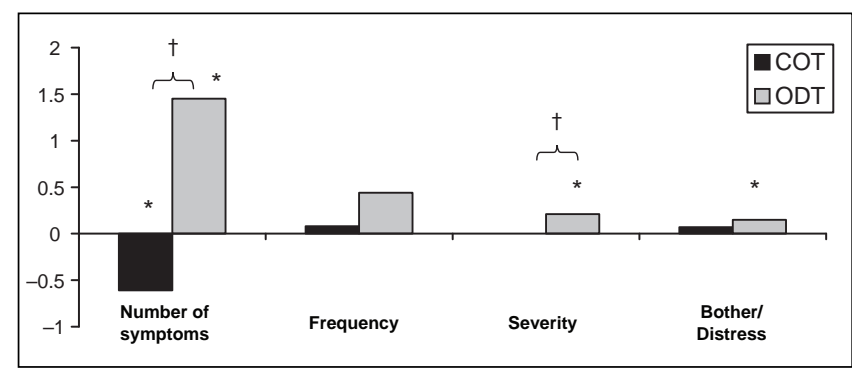

Figure 3) Change in gastroesophageal reflux disease symptoms assessment scale (14) score between the baseline and final week of the maintenance phase. $* P<0.05$ for the difference between the final visit and randomization; ${ }^{\dagger} \mathrm{P}<0.05$ for the difference between continuous therapy (COT) and on-demand therapy (ODT) groups

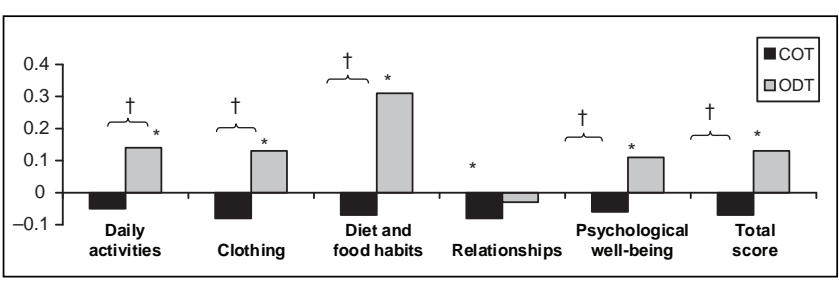

Figure 4) Change in patient assessment of upper gastrointestinal disorder - quality of life questionnaire (15) scores between the baseline (randomization) and last week of the maintenance phase. $* P<0.05$ for the difference between the final visit and randomization; ${ }^{\dagger} \mathrm{P}<0.05$ for difference between continuous therapy (COT) and on-demand therapy (ODT) groups

on PPIs at study entry, and had to demonstrate satisfactory symptom control at the end of the acute phase, before randomization into the maintenance phase).

At the end of the maintenance treatment phase, there was a significant improvement in mean number of GERD symptoms for COT $(\mathrm{P}<0.05)$, and a slight decline in symptom control, as noted by increased scores, compared with randomization baseline for all other GSAS subscores. The exception was symptom severity, which stayed the same; however, these changes were not statistically significant and may not be clinically significant. In comparison, statistically significant reductions in symptom control from randomization baseline were observed for the ODT group for all GSAS subscores, with the exception of symptom frequency (Figure 3). Those taking COT experienced significantly fewer and less severe GERD symptoms at the final visit than those taking ODT.

At the end of the maintenance treatment phase, there was an overall improvement in quality of life, as noted by decreases in the PAGI-QOL total and all domain scores reported for those taking COT; however, those within-group decreases were not statistically significant, with the exception of the relationships domain score $(\mathrm{P}=0.04)$. There was a significant withingroup decline in quality of life from randomization baseline observed for the ODT group for PAGI-QOL total and domain scores, with the exception of the relationships domain score $(P=0.4)$ (Figure 4). Significant differences were noted between treatment groups, with the COT group experiencing greater improvement in PAGI-QOL total score $(\mathrm{P}=0.0003)$ and all domain scores except relationships $(\mathrm{P}=0.3)$.

Overall treatment evaluation: Regardless of regimen, the majority of patients rated the effect of the study medication on heartburn control as 'good' or 'very good', with no significant difference noted between treatment groups (COT 89\% versus ODT 83\%; 
$\mathrm{P}=0.2803$ ). The physicians' assessment was similar, with $89 \%$ of physicians rating the overall effect of the study medication on heartburn control as 'good' or 'very good' for COT, and $81 \%$ for ODT $(\mathrm{P}=0.1173)$. Significantly more subjects on COT rated themselves 'satisfied' or 'very satisfied' with the effect that their medication regimen had on heartburn control than those on ODT (92\% and 79\%, respectively; $\mathrm{P}=0.0070$ ).

\section{Safety}

The safety analysis included the 268 patients randomly assigned to two treatment groups (COT, $n=137$; ODT, $n=131$ ).

Table 2 lists the most frequent adverse events occurring in 3\% or more of patients in the maintenance phase, regardless of relationship to study medication. A total of seven subjects (nine events) in the COT group only reported adverse events considered to be related to the study medication, namely: bloating, abdominal cramps, stomach ache, worsening of constipation, diarrhea, epigastric discomfort, memory impairment, itchy sensation of extremities and itchy skin. These events were categorized as either mild or moderate by the reporting investigator, except for one severe case of epigastric discomfort. Five patients discontinued the maintenance phase as a result of nonserious adverse events (four patients in the COT group and one patient in the ODT group); all recovered without sequelae. Adverse event(s) that led to withdrawal included aggravation of palpitations $(n=1)$, memory impairment $(n=1)$, abdominal cramps $(n=2)$, bloating $(n=1)$, heartburn $(n=1)$, stomach ache $(n=1)$, abdominal cramps $(n=2)$ and diarrhea $(n=2)$. Memory impairment was categorized as possibly related to study medication, and abdominal cramps, stomach ache, bloating and diarrhea were categorized as probably related. There were six serious adverse events reported during the study, namely, postoperative tonsillectomy hemorrhage, malignant melanoma, atrial fibrillation, headache, skin cancer and intestinal infection; all were deemed not related to study medication. There were no clinically or statistically significant changes in vital signs (pulse and blood pressure) or weight observed during the study.

\section{DISCUSSION}

The present study evaluated both COT and ODT maintenance regimens of rabeprazole therapy to provide clinicians with insight into the optimal course of long-term therapy for uninvestigated GERD.

Good, predictable control was achieved with rabeprazole $20 \mathrm{mg}$ continuous therapy. While the study results indicate that there were more frequent and severe episodes of heartburn with ODT compared with COT, when symptoms did occur during ODT, they were generally of short duration and were easily treated, resulting in rapid symptom resolution. Results also indicated low rescue antacid usage in both treatment groups.

Based on these findings, COT is more likely to provide predictably better heartburn symptom control than ODT in uninvestigated GERD; however, both regimens achieved satisfactory heartburn control on all assessments measured, and both treatment regimens were safe and well-tolerated by patients.

In general, previous trials that have compared ODT with COT in the long-term management of GERD have reported that continuous PPI treatment was better than ODT for maintaining symptom control in healed erosive esophagitis (16), but reported no significant difference between continuous and on-demand regimens for mildly erosive disease (17). The clear

\begin{tabular}{|c|c|c|}
\hline Adverse event & COT n (\%), n=137 & ODT $n(\%), n=131$ \\
\hline Sinusitis & $4(<3)$ & $8(6.1)$ \\
\hline Upper respiratory infection & $12(8.8)$ & $9(6.9)$ \\
\hline Common cold & $5(3.7)$ & $6(4.6)$ \\
\hline Bronchitis & $6(4.4)$ & $5(3.8)$ \\
\hline Diarrhea & $5(3.7)$ & $3(<3)$ \\
\hline Headache & $3(<3)$ & $4(3.1)$ \\
\hline Influenza & $1(<3)$ & $4(3.1)$ \\
\hline
\end{tabular}

COT Continuous therapy; ODT On-demand therapy

difference in symptom control observed between continuous and on-demand regimens reported in the current study may be attributable to the fact that the patient population was not investigated with endoscopy before treatment initiation and, as a result, was likely a mix of patients with nonerosive disease and those with varying degrees of erosive esophagitis. This difference is also consistent with clinical experience, where the cessation of continuous acid suppression therapy results in recurrence of heartburn in some patients.

The proportion of patients discontinuing ODT due to inadequate heartburn control, while greater than that observed for COT in this study (4.6\% versus $2.2 \%$ ), was lower than that reported in several studies with other PPIs: $17 \%$ with omeprazole $20 \mathrm{mg}$ (9) and 14\% with esomeprazole $20 \mathrm{mg}$ (4), and was comparable to the discontinuation rate of $6 \%$ observed by Bytzer et al (7).

In a recent review by Lee et al (18), it was noted that a substantial proportion ( $26 \%$ to $71 \%$ ) of GERD patients can be "adequately managed" with less than daily PPI treatment. However, these conclusions are based on patients' reporting of satisfaction with their symptom control and their level of willingness to continue on less intensive therapy. When more formal measures, such as health-related quality of life and detailed symptom assessments, including severity and frequency of symptoms, are utilized to evaluate treatment efficacy, inadequate symptom management may be observed with noncontinuous regimens and, thus, may not support such treatment (18).

The present study did not assess endoscopic, esophageal status of patients enrolled and, therefore, could not relate esophageal inflammation to symptom control and response. Because of the lack of endoscopic data, the current results may include both erosive and nonerosive GERD patients, leading to potential heterogeneity in the participating patient population.

Heartburn was the predominant symptom used for eligibility determinations and was the symptom measured in most efficacy analyses. While heartburn is a fairly specific symptom of GERD, other symptoms may exist that should be considered for diagnosis and treatment. Given this consideration, patients who did not have acid reflux disease at all could have been included. Approximately 50\% of patients with such nonulcer dyspepsia may still respond to acid suppression therapy (12). However, in everyday practice, the bulk of patients with GERD do not undergo endoscopic assessment, hence, selection methodology for this study mirrors general practice and makes these results more generalizable. 
Similarly, the present study did not address other reasons why patients may choose maintenance ODT, such as a preference for being in control of their treatment, decreased medical intervention, less drug exposure or decreased costs.

In a recent study by Remak et al (2), rabeprazole was less costly and resulted in more symptom-free days than other PPIs (excluding generic omeprazole); rabeprazole also remained cost-effective, independent of choice of maintenance treatment (COT or ODT). In the current study, cost effectiveness was not evaluated, nor were quality adjusted life years examined; however, a potential pharmacoeconomic consideration for future studies might be whether continuous treatment could be justified on the basis of more quality adjusted life years versus on-demand therapy. Based on the efficacy results observed in the present study, there would have to be a willingness on the part of the patient to compromise between the improvement in symptom control that could be expected with COT with the potential cost advantage of ODT. This strategy may be appropriate for selected patients.

\section{CONCLUSION}

Following successful short-term therapy with rabeprazole $20 \mathrm{mg}$ to control GERD symptoms, the current findings, based primarily on symptom control, favour maintenance COT over ODT for uninvestigated GERD. However, both treatment regimens

\section{REFERENCES}

1. Zacny J, Zamakhshary M, Sketris I, Veldhuyzen van Zanten S. Systematic review: The efficacy of intermittent and on-demand therapy with histamine $\mathrm{H} 2$-receptor antagonists or proton pump inhibitors for gastro-oesophageal reflux disease patients. Aliment Pharmacol Ther 2005;21:1299-312.

2. Remak E, Brown RE, Yuen C, Robinson A. Cost-effectiveness comparison of current proton-pump inhibitors to treat gastrooesophageal reflux disease in the UK. Curr Med Res Opin 2005;21:1506-17.

3. Armstrong D, Marshall JK, Chiba N, et al, for the Canadian Association of Gastroenterology GERD Consensus Group. Canadian Consensus Conference on the management of gastroesophageal reflux disease in adults - update 2004. Can J Gastroenterol 2005;19:15-35.

4. Talley NJ, Lauritsen K, Tunturi-Hihnala H, et al. Esomeprazole $20 \mathrm{mg}$ maintains symptom control in endoscopy-negative gastrooesophageal reflux disease: A controlled trial of 'on-demand' therapy for 6 months. Aliment Pharmacol Ther 2001;15:347-54.

5. Dent J, Talley NJ. Overview: Initial and long-term management of gastro-oesophageal reflux disease. Aliment Pharmacol Ther 2003;17(Suppl 1):53-7. Review

6. Howden CW, Henning JM, Huang B, Lukasik N, Freston JW. Management of heartburn in a large, randomized, community-based study: Comparison of four therapeutic strategies. Am J Gastroenterol 2001;96:1704-10. (Erratum in Am J Gastroenterol 2001;96:2809).

7. Bytzer P, Blum A, De Herdt D, Dubois D, for The Trial Investigators. Six-month trial of on-demand rabeprazole $10 \mathrm{mg}$ maintains symptom relief in patients with non-erosive reflux disease. Aliment Pharmacol Ther 2004;20:181-8.

8. Ponce J, Arguello L, Bastida G, Ponce M, Ortiz V, Garrigues V. On-demand therapy with rabeprazole in nonerosive and erosive gastroesophageal reflux disease in clinical practice: Effectiveness, health-related quality of life, and patient satisfaction. Dig Dis Sci 2004;49:931-6. can be considered effective and safe options. Selection of individual optimal therapy should consider not only symptom control but patient preference.

ACKNOWLEDGEMENTS: Principal Investigators for the RAB-GRD-3001 study group: Dr DG Morgan, Coordinating Investigator (Hamilton, Ontario); Dr G Achyuthan (Regina, Saskatchewan); Dr M Audet (Ste-Foy, Quebec); Dr S Behiels (Edmonton, Alberta); Dr S Brault (Granby, Quebec); Dr B Carlson (Coquitlam, British Columbia); Dr HS Conter (Halifax, Nova Scotia); Dr D Dattani (Saskatoon, Saskatchewan); Dr S Ebrahim (Toronto, Ontario); Dr FD Fraser (Stoney Creek, Ontario); Dr Roger D Hamilton (Toronto, Ontario); Dr AJ Kelly (Edmonton, Alberta); Dr KF Luces (Whitby, Ontario); Dr JDR McMorran (Toronto, Ontario); Dr KK Misik (Toronto, Ontario); Dr MFJ O'Mahony (Sarnia, Ontario); Dr WF O'Mahony (Corunna, Ontario); Dr F Onuska (Kitchener, Ontario); Dr BR Ramjattan (St John's, Newfoundland); Dr J Roy (Les Saules, Quebec); Dr RW Senior (North Bay, Ontario); Dr R Somani (Langley, British Columbia); and Dr BS Zidel (Mississauga, Ontario).

DATA SUPPORT: J Sigindere, R Lachhman and R Manuel.

FUNDING SUPPORT: This work was supported by JanssenOrtho Inc, Toronto, Ontario.

9. Lind T, Havelund T, Lundell L, et al. On demand therapy with omeprazole for the long-term management of patients with heartburn without oesophagitis - a placebo-controlled randomized trial. Aliment Pharmacol Ther 1999;13:907-14.

10. Junghard $O$, Carlsson R, Lind T. Sufficient control of heartburn in endoscopy-negative gastro-oesophageal reflux disease trials. Scand J of Gastroenterol 2003;33:1197-9.

11. ICH Secretariat. International Conference on Harmonization of Technical Requirements for Registration of Pharmaceuticals for Human Use. ICH Harmonised Tripartite Guideline for Good Clinical Practice, 1997.

12. Veldhuyzen van Zanten SJO, Flook N, Chiba N, et al. An evidence-based approach to the management of uninvestigated dyspepsia in the era of Helicobacter pylori. Canadian Dyspepsia Working Group. CMAJ 2000;162(12 Suppl):S3-23.

13. Carlsson R, Dent J, Bolling-Sternevald E, et al. The usefulness of a structured questionnaire in the assessment of symptomatic gastroesophageal reflux disease. Scand J Gastroenterol 1998;33:1023-9

14. Rothman M, Farup C, Stewart W, Helbers L, Zeldis J. Symptoms associated with gastroesophageal reflux disease: Development of a questionnaire for use in clinical trials. Dig Dis Sci 2001;46:1540-9.

15. De la Loge C, Rentz A, Dubois D, Jones B, Peeters K, Marquis P. Development and initial psychometric validation of the patient assessment of upper gastrointestinal disorders - quality of life instrument (PAGI-QOL) in GI patients. Value Health 2000;3:358.

16. Sjöstedt S, Befrits R, Sylvan A, et al. Daily treatment with esomeprazole is superior to that taken on-demand for maintenance of healed erosive oesophagitis. Aliment Pharmacol Ther 2005;22:183-91.

17. Kao A, Sheu B, Sheu M, et al. On-demand therapy for Los Angeles grade A and B reflux esophagitis: Esomeprazole versus omeprazole. J Formos Med Assoc 2003;9:607-12.

18. Lee TJ, Fennerty MB, Howden CW. Systematic review: Is there excessive use of proton pump inhibitors in gastro-oesophageal reflux disease? Aliment Pharmacol Ther 2004;20:1241-51. 


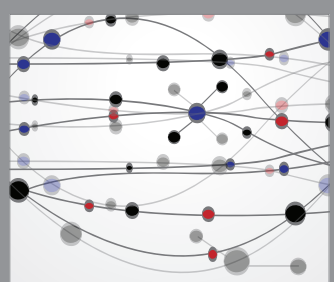

The Scientific World Journal
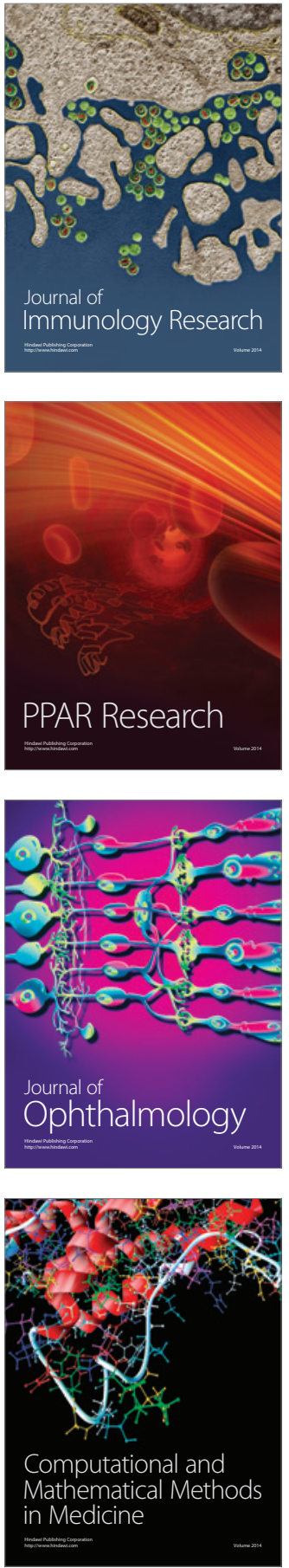

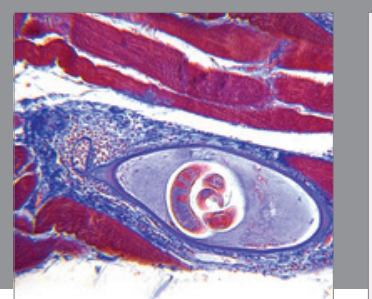

Gastroenterology Research and Practice

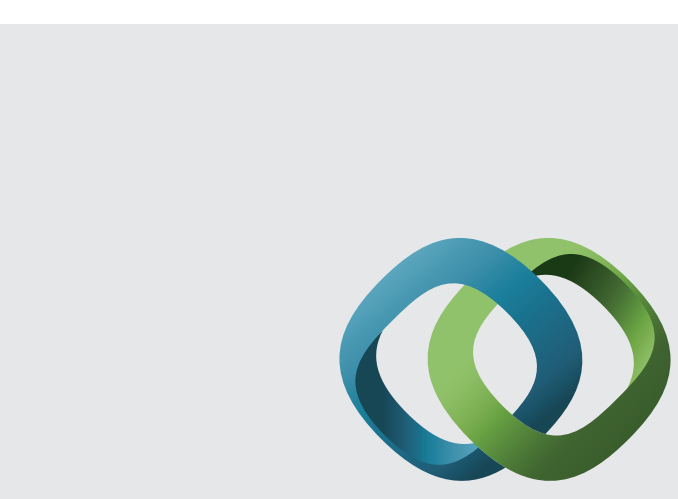

\section{Hindawi}

Submit your manuscripts at

http://www.hindawi.com
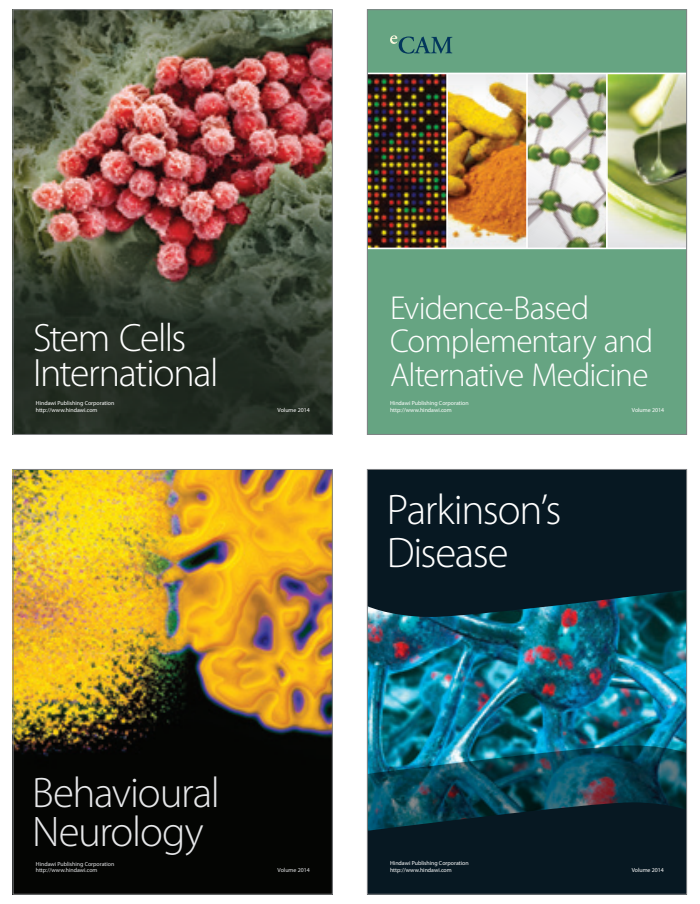
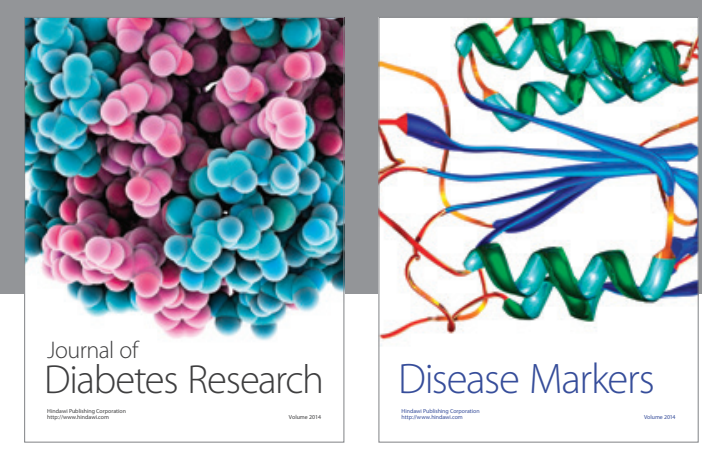

Disease Markers
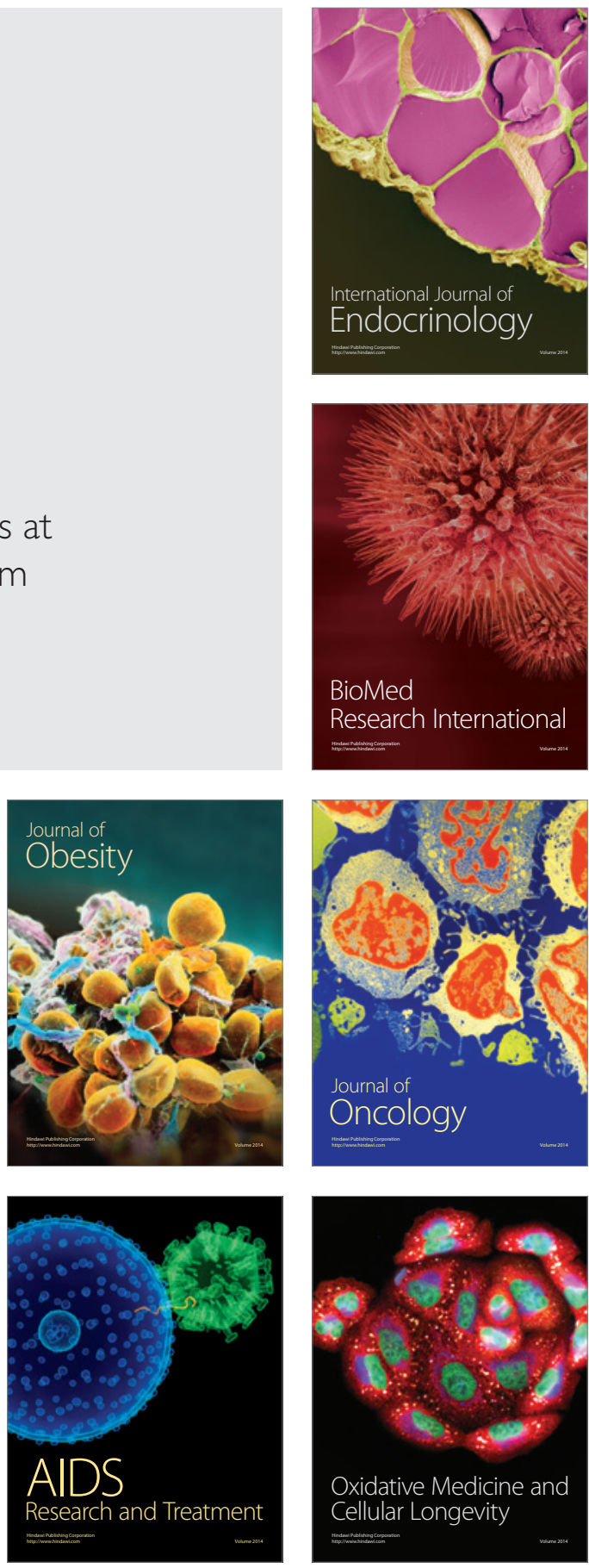